BJHS: Themes 1: 61-82, 2016. C British Society for the History of Science 2016. This is an Open Access article, distributed under the terms of the Creative Commons AttributionNonCommercial-NoDerivatives licence (http://creativecommons.org/licenses/by-nc-nd/4.0/), which permits non-commercial re-use, distribution, and reproduction in any medium, provided the original work is unaltered and is properly cited. The written permission of Cambridge University Press must be obtained for commercial re-use or in order to create a derivative work. doi:10.1017/bjt.2016.1 First published online 22 March 2016

\title{
Accepting difference, seeking common ground: Sino-Indian statistical exchanges 1951-1959
}

\author{
ARUNABH GHOSH*
}

\begin{abstract}
Starting as early as 1951, and with increasing urgency after 1956, Chinese and Indian statisticians traded visits as they sought to learn from each other's experiences. At the heart of these exchanges was the desire to learn more about a cutting-edge statistical method, random sampling, which, while technically complex, held great practical salience for large and diverse countries such as China and India. This paper draws upon unpublished documents, letters, institutional archives, memoirs, oral history and newspaper reports to reconstruct the sequence of these exchanges, their outcomes and the concerns of the participants. The exchanges demonstrate not only the crucial role played by Indian statisticians in the rise of random sampling, but also the amount of resistance these methods generated in places like China (and the Soviet Union). As a clear instance of South-South scientific exchange, they also compel a broadening of our understanding of early Cold War scientific networks, which should no longer be dominated by centre-periphery models that take either the USSR or the US as the centre. Finally, the exchanges hint at the varied nature of post-1949 Sino-Indian history, a subfield still dominated by geopolitics and a focus on the causes, course and legacy of the SinoIndian War of 1962.
\end{abstract}

Sunday, 9 December 1956. Chinese premier Zhou Enlai's visit to the Indian Statistical Institute (ISI) in Calcutta had not gone entirely according to schedule. The original itinerary called for a visit of half an hour. Strenuous protestations by Prasanta Chandra Mahalanobis (1893-1972), the ISI's director, had resulted in a further forty-five minutes being granted. But the premier's party arrived almost a half-hour late, throwing the carefully planned schedule into disarray. Various items on the agenda had to be jettisoned. ${ }^{1}$ Zhou himself did not help matters by getting deeply involved in several displays, asking questions, seeking clarifications. In the National Sample Survey Unit, he sat down on a table and refused to move until his questions had been satisfactorily answered. By the time he finally emerged out in the open, well behind schedule, the officials who had accompanied Zhou through his tour of the Institute were all in a hurry to

* Center for Government and International Studies, South Building, Room S135, 1730 Cambridge Street, Cambridge, MA 02138, United States. Email: aghosh@fas.harvard.edu.

Research for this paper was supported by grants from the American Council of Learned Societies, the Social Science Research Council and Columbia University. I would also like to thank the participants of the Intersections workshop and the anonymous reviewers for their trenchant feedback on earlier drafts.

1 Foreign Ministry Archives, Beijing (subsequently FMA), File 203-00084-01, 118. 
depart. Suddenly, Zhou caught hold of Mahalanobis's arm, 'side-stepped the waiting car, waved his hand to shake off everyone', and took him aside.

'What are the countries most advanced in statistics? Are you in touch with them?' Zhou inquired. Mahalanobis listed the United Kingdom, the United States and the Soviet Union, noting further that while they had been in touch with all three, it was not desirable to copy from any country and that 'in India we are trying to adopt and develop the methods to suit our own needs'. Zhou nodded his head in approval. He observed that a group of Chinese statisticians would be visiting the ISI very soon: 'I want them to see everything in detail. We want to learn from you ... Also, we want to send research scholars to work here. What is the kind of men who should come?' Mahalanobis told Zhou that he wanted a mix of types, some advanced and some with good experience of practical work. He also wanted an economist or two who could share China's planning experiences. Zhou again approved. 'Yes, we must have exchange of men.' He ended the conversation by taking Mahalanobis's two hands in his and stating very firmly, 'and next year in Peking'. ${ }^{2}$

This exchange not only is remarkable, but also makes no sense. It is remarkable because for the 1950s we tend to think of the PRC's interaction with the outside world in the areas of science and technology as being entirely framed by its alliance with the Soviet Union and the socialist bloc. Largely in keeping with this logic, the Chinese had rejected an invitation from Mahalanobis to join an Asian Statistical Association in 1951. As a Foreign Ministry telegram from Beijing to the Chinese embassy in Delhi had then noted,

The [stated] Association has extremely close ties with the international statistics society, operates under the influence and control of imperialism, and there is a great probability that in the name of learning and science it will be used to conduct intelligence[-related] activities. ${ }^{3}$

Just as significantly, though, it makes no sense because statistics at the Indian Statistical Institute was precisely the kind of probabilistic statistics identified with the West that the Chinese had been rejecting on theoretical grounds since 1949 and would, for the most part, continue to reject until the early years of the Deng Xiaoping era (1978-). As Li Fuchun 李富春 (1900-1975), then the deputy head of the Central Economic and Financial Commission, had declared in 1951, 'Statistics in Old China was learned from the Anglo-American bourgeoisie. This kind of statistics cannot serve as our weapon, it is unsuitable for [the tasks of] managing and supervising the country ... we need to build a [new] statistics for a new China'. He then went on to add that this new statistics must 'only rely on studying the Soviet model of socialism, and use the weapon of Marxist-Leninist statistics'. ${ }^{4}$

And yet, by 1956 Zhou's urgency was real and the results tangible. Just two days after his visit, a team of Chinese statisticians arrived at the ISI. Ostensibly there to participate in the silver jubilee celebrations of the ISI, the team stayed for a month. Led by one of the

2 P.C. Mahalanobis to Pitambar Pant, 16 December 1956, P.C. Mahalanobis Memorial Museum and Archive (subsequently PCMMMA), File No 915, 1953-1956.

3 FMA 105-00229-01, 45.

4 Li Fuchun 李富春, 'Speech at the 1st National Statistics Meeting', Beijing, 1951. 
deputy directors of the State Statistics Bureau (SSB), Wang Sihua 王思华 (1904-1978), the four-person delegation also included the noted demographer, statistician and Renmin University professor Dai Shiguang 戴世光 (1908-1999). Within months of returning to Beijing, deliberations over inviting Mahalanobis to China began. 'And next year in Peking' did indeed become a reality. Mahalanobis and the statistician D.B. Lahiri spent three weeks in China during the summer of 1957. They lectured to large audiences, held numerous discussions, and planned future cooperation and exchange. Later that year, two Chinese statisticians, Wu Hui 吴辉 from the Industrial Statistics Division and Gong Jianyao 龚鉴尧 from the Agricultural Statistics Division, arrived at the ISI and spent over a year in India studying statistical theory and its applications.

At the heart of the Sino-Indian exchanges was the desire to learn more about mathematical statistics and its applications, particularly the cutting-edge statistical method of random sampling. While technically complex, random sampling held great practical salience for large and diverse countries such as China and India. This essay traces these exchanges, explaining their timing and the motivation behind them. In so doing, it brings together three historiographical themes that would not normally be considered together. The first of these has to do with the history of statistics and the expansion to the point of ubiquity today of large-scale probabilistic methods like randomized survey sampling. The Sino-Indian statistical exchanges of the 1950s demonstrate to us not just the crucial role played by Indian statisticians in that process, but also the amount of resistance these methods generated in places like China and the Soviet Union. The rise to dominance of probabilistic statistical methods and of quantitative positivism in the twentieth century is far from a monolithic story, and it would be useful to bear that in mind as we experience our latest iteration of (big-)data enthusiasm.

The Sino-Indian exchanges also provide a specific and highly illuminating case of the growing disaffection that the Chinese experienced with a strategy of overt reliance on the Soviet Union for technical and scientific advice. Indeed, most studies of the Sino-Soviet split tend to focus on top-down factors such as the role of ideology, the impact of the Hungarian Revolt and its repression, Khrushchev's speech denouncing the cult of Stalin (de-Stalinization), or internal struggles between Mao and other top Chinese leaders. ${ }^{5}$ To these we must add bottom-up factors such as substantive disaffection with Soviet methods and the theory behind them. At the same time, by identifying a clear instance of South-South scientific exchange between China and India, these findings also compel us to reassess our understanding of early Cold War scientific networks,

5 The Sino-Soviet alliance has been the subject of renewed interest in recent years, resulting in studies that approach the alliance and its collapse from a multiplicity of perspectives. For some representative works see Thomas P. Bernstein and Hua-yu Li (eds.), China Learns from the Soviet Union, 1949-Present, New York: Lexington Books, 2000; Austin Jersild, Sino-Soviet Alliance: An International History, Chapel Hill: University of North Carolina Press, 2014; Lorenz Lüthi, The Sino-Soviet Split: Cold War in the Communist World, Princeton, NJ: Princeton University Press, 2008; and Odd Arne Westad, Brothers in Arms: The Rise and Fall of the Sino-Soviet Alliance, 1945-1963, Stanford, CA: Stanford University Press, 1998. 
which should no longer be dominated by centre-periphery models with either the USSR or the US at the centre. ${ }^{6}$

Finally, the exchanges call for a reorientation of post-1949 Sino-Indian history, a subfield still dominated by geopolitics and a focus on the causes, course and legacy of the SinoIndian War of 1962. These exchanges are very likely one of a whole range of contact, cooperation and mutual assessment that we remain remarkably ignorant about. A fundamental reappraisal of the decade, beginning with the rediscovery of such long-forgotten episodes and exchanges, thus has the potential not only to offer fresh perspectives on the early years of the Cold War, but also to contribute to the histories of India and China.

\section{P.C. Mahalanobis and the promise of large-scale random sampling}

Until the end of the nineteenth century, the evolution of statistics had progressed on two parallel tracks, one descriptive and the other analytic. ${ }^{7}$ The descriptive traced its origins to the 'political arithmetic' of the seventeenth century, and through it to a much more fundamental and age-old phenomenon - the desire of the state to collect information about its constituents, its land and its produce. The analytic can be traced at least as far back as the sixteenth and seventeenth centuries and was principally concerned with concepts of chance, probability and estimating and controlling error, all in an abstract, mathematical sense. Starting in the nineteenth century, these tracks began to intersect. Statistical methods were brought to bear on the most pressing social concerns of the day. This cross-pollination led to tremendous innovation, resulting in many of the concepts that form the bedrock of modern-day statistics - correlation, variance, regression and random sampling. ${ }^{8}$

By the 1940s, statistics, operations research and other numerically driven methods of understanding and organizing different aspects of day-to-day life had begun to gain legitimacy. The end of the Second World War witnessed new attempts at global organization, and coincided with the post-colonial wave of newly independent countries. Statistics came to be viewed as a key tool for national and international development and stability. Newly formed nation states sought to establish statistical bureaus,

6 There is a growing literature on the history of development and aid in the post-Second World War era, much of it through the prism of US- or Soviet-centred networks of aid and influence. Representative works include Nick Cullather, The Hungry World: America's Cold War Battle against Poverty in Asia, Cambridge, MA: Harvard University Press, 2010; David Ekbladh, The Great American Mission: Modernization and the Construction of an American World Order, 1914 to the Present, Princeton, NJ: Princeton University Press, 2010; Daniel Immerwahr, The Village Ideal: The United States, Community Development, and the World, Cambridge, MA: Harvard University Press, 2014; Westad, op. cit. (5); and Bernstein and Li, op. cit. (5). Among the latest works to offer a somewhat different framework is Jeremy Friedman, Shadow Cold War: The Sino-Soviet Competition for the Third World, Chapel Hill: University of North Carolina Press, 2015.

7 P.C. Mahalanobis, 'Why Statistics?', Sankhya: The Indian Journal of Statistics (1950) 10(3), pp. 195-228, 195-196.

8 For more on this fairly well-documented history see, in particular, Ian Hacking, The Taming of Chance, Cambridge: Cambridge University Press, 1990; Theodore Porter, The Rise of Statistical Thinking, 1820-1900, Princeton, NJ: Princeton University Press, 1986; Porter, Trust in Numbers: The Pursuit of Objectivity in Science and Public Life, Princeton, NJ: Princeton University Press, 1995. 
collect data and address issues of governance and growth. At the global level, newly formed international organizations like the United Nations and the World Bank sought to render such data commensurable by establishing norms for their collection, collation and analysis. ${ }^{9}$

Prasanta Chandra Mahalanobis was among the most articulate spokesmen for the promotion and use of statistics. 'A physicist by training, a statistician by instinct and a planner by conviction', Mahalanobis combined scientific and intellectual heft with a tremendous drive to engage in practical matters. ${ }^{10}$ As a result, he became intrinsically involved not just with independent India's first forays into economic planning and development, but, perhaps even more significantly, also with the development and establishment of statistics, most notably sample survey techniques, as a principal tool for knowing the world. ${ }^{11}$ Mahalanobis's original training had been in physics, and it was a subject he continued to teach into the 1950s. But a chance encounter with statistical journals in a Cambridge University library led to his first exposure to statistics. By the mid-1920s he had abandoned plans to return to Cambridge, choosing instead to stay in Calcutta and apply statistical methods to practical problems. In 1932, along with a few like-minded individuals, he established the Indian Statistical Institute (ISI) in Calcutta. Operating initially out of a tiny room in Presidency College, by the 1950s the ISI had moved to a sprawling campus in the north of the city and evolved into one of the premier centres for statistical research and application across the globe.

In his Presidential Address to the Indian Science Congress in January 1950, Mahalanobis had observed that 'at each upsurge of social and political development, or during war, there is a rapid growth and expansion of statistical practice'. ${ }^{12}$ To his mind, the 1940s and 1950s were precisely such a time. Wartime exigencies had spurred the application of statistical theory to practical problems, and now, in the post-war world, statistics had a foundational role to play. In 1947, he brought this enthusiasm to the UN's newly formed Statistical Commission and served as the chairman of its Sub-commission on Statistical Sampling. ${ }^{13}$ As Jelke Bethlehem has noted, Mahalanobis was the driving force behind the sub-commission, convinced that 'sampling methods could overcome the otherwise insoluble problems of obtaining accurate information about a vast and still largely illiterate country like India'. ${ }^{14}$

9 For a history of the UN and its role in this process see Michael Ward, Quantifying the World: UN Ideas and Statistics, Bloomington: Indiana University Press, 2004.

10 C.R. Rao, 'Prasantha Chandra Mahalanobis, 1893-1972', Biographical Memoirs of Fellows of the Royal Society (1973) 19, pp. 454-492, 455.

11 A useful overview of Mahalanobis's activities and achievements is Rao, op. cit. (10). For a longer treatment see Ashok Rudra, Prasanta Chandra Mahalanobis: A Biography, New Delhi: Oxford University Press, 1996.

12 Mahalanobis, op. cit. (7), pp. 196.

13 The commission is the 'highest body of the global statistical system ... It is the highest decision making body for international statistical activities especially the setting of statistical standards, the development of concepts and methods and their implementation at the national and international level', at http://unstats.un. org/unsd/statcom, accessed 21 January 2016.

14 Jelke Bethlehem, The Rise of Survey Sampling, discussion paper 09015, The Hague: Statistics Netherland, 2009. 
Sampling, of course, has a long history. In his 1950 Presidential Address Mahalanobis had explained that its twentieth-century formulation was a combination of the long history of purposive sampling with that of recent developments in probability and mathematics. Purposive sampling is a form of sampling in which the samples chosen for analysis are selected because of some specific characteristic they possess. Today, we would identify it more closely with qualitative, supervised research, not quantitative. For a long time it was regarded as the only proper method of sampling and as late as 1926 it was given considerable prominence by a committee of experts of the International Statistical Institute. ${ }^{15}$ But since then evidence had been consistently mounting that it produced results that were neither representative nor accurate. The method of complete enumeration was also brought under increased scrutiny. In a 1950 paper in the Bulletin of the International Statistical Institute Mahalanobis had demonstrated 'that with an acceptable level of precision the costs of [random] sample surveys are only about ten percent of that of a complete enumeration' ${ }^{16}$ In the same issue, Mahalanobis's friend, collaborator and colleague on the sub-commission, the statistician Ronald A. Fisher, went even further and stated not only that sampling procedures were ideal because of their adaptability, speed and economy, but also that they were more scientific than complete enumeration. ${ }^{17}$ Mathematical theory undergirded sampling, and this permitted, to cite Bethlehem again, the 'careful design of sample surveys with a pre-set level of precision'. ${ }^{18}$

Mahalanobis and his colleagues at the ISI made three notable contributions to the development of large-scale sample survey techniques. ${ }^{19}$ These were the introduction of pilot surveys, the concept of optimum survey design, and the use of interpenetrating networks of samples. ${ }^{20}$ They developed these methods during the 1930s and 1940s, starting initially by using sampling procedures to estimate jute yield in Bengal in 1937. Mahalanobis's contributions were not limited to the development of theory and method alone, and he also assisted in establishing the framework and standards

15 Rao, op. cit. (10), p. 472.

16 Bethlehem, op. cit. (14), p. 16.

17 Ronald Aylmer Fisher (1890-1962) was a statistician, geneticist and evolutionary biologist, whose contributions in statistics include the analysis of variance (ANOVA), the method of maximum likelihood, the derivation of various sampling distributions, and experimental design. As a result of these contributions, many regard him as one of the principal creators of modern statistics. For more see F. Yates and K. Mather, 'Ronald Aylmer Fisher 1890-1962', Biographical Memoirs of Fellows of the Royal Society (1963) 9, pp. 91-129.

18 Bethlehem, op. cit. (14), p. 16.

19 The mathematical statistician Harold Hotelling observed, 'No technique of random samples has, so far as I can find, been developed in the United States or elsewhere, which can compare in accuracy with that described by Professor Mahalanobis.' Fellow statistical luminary R.A. Fisher noted, 'The I.S.I. has taken the lead in the original development of the technique of sample surveys, the most potent fact finding process available to the administration.' See: Rao, op. cit. (10), pp. 472.

20 Rao, op. cit. (10), pp. 473. Within India, Mahalanobis had no dearth of detractors. For more on his critics and alternative approaches to sampling see A.P. Gore, 'P.V. Sukhatme: A “Social” Statistician', Economic and Political Weekly (1997) 32(6), pp. 257-258. Among those who took strong exception to Mahalanobis's domination of Indian statistics were the scientists Homi J. Bhabha and D.D. Kosambi. For more see Kosambi to Bhabha, Tata Institute for Fundamental Research, D-2004-0387-5 and D-2004-0387-8. 
through which they could be used across the world. As chairman of the UN Sub-commission on Statistical Sampling, he oversaw the publication of The Preparation of Sample Survey Reports, which continues to provide common guidelines for modern sampling procedures in use by statistical bureaus across the world today. ${ }^{21}$

Mahalanobis's interest in statistics was almost entirely instrumental, a point he made most forcefully in his essay 'Statistics must have a purpose'. ${ }^{22}$ This desire to use statistics to solve real-world problems also got him involved in economic planning and institution building. India's prime minister, Jawaharlal Nehru, appointed him to the Planning Commission, and before long he was charged with drawing up India's second Five Year Plan (1955-1959). In preparation for this work Mahalanobis spent the summer of 1954 traveling through the United States, the United Kingdom, Eastern Europe and the Soviet Union, conferring with economists, statisticians and planners. A two-sector growth model that he had created in 1953, similar to G.A. Feldman's 1928 model, became the basis for India's second Five Year Plan. ${ }^{23}$ Earlier in the decade, he had succeeded in bringing the twenty-seventh biennial Conference of the International Statistical Institute to New Delhi in December 1951.24 With the exception of Japan, which had played host in 1930, this marked the first time that an Asian or African nation had hosted the conference. By the 1950s Mahalanobis had also built the ISI up to be one of the leading centres for statistical innovation in the world. It was a magnet for scientists of all kinds, from either side of the Iron Curtain and beyond. ${ }^{25}$ And with the help of UNESCO, in 1950 he had set up at the ISI an International Statistical Education Centre (ISEC), the principal purpose of which was to train statistical workers and students from Asia and Africa. By 1956, students from fourteen or fifteen countries were receiving training at the centre. ${ }^{26}$

21 United Nations Statistical Commission, 'The preparation of sampling survey reports', Statistical Papers, Series C, No 1, Lake Success, New York, 1950. A follow-up report was published in 1964, with Mahalanobis serving as the sub-commission's vice chairman. See United Nations Statistical Commission, 'Recommendations for the preparation of sampling survey reports (provisional issue)', Statistical Papers, Series C, No 1, Rev. 2, New York, 1964.

22 P.C. Mahalanobis, 'Statistics must have a purpose', Samvadadhvam, July 1956, pp. 3-10.

23 On alternatives to the Mahalanobis model and on contemporary debates surrounding planning strategies see Meghnad Desai, 'Development perspectives: was there an alternative to Mahalanobis?', in Isher Judge Ahluwalia (ed.), India's Economic Reforms and Development: Essays for Manmohan Singh, New Delhi: Oxford University Press, 2012, pp. 43-52.

24 Mahalanobis had tried to bring the conference to India in 1949, but Switzerland's invitation was favoured instead. See File EA/UN-I/9(58)-UNI, 1949, National Archives of India, New Delhi.

25 The ISI annual reports carry long lists of visiting scientists of varying disciplinary and ideological persuasions. Mahalanobis himself was a great traveller and the annual reports usually also devoted a few pages to his global travels. By the end of the decade, some exasperated friends and colleagues began to worry that the administration of the ISI was suffering as a result. In 1960 this issue even drove J.B.S. Haldane, then a full-time professor at the institute, to quit in protest. For more on Haldane and Mahalanobis see Ramachandra Guha, An Anthropologist among Marxists and Other Essays, New Delhi: Permanent Black, 2001, pp. 134-135.

26 'Professor Mahalanobis welcomes Chou En-Lai', Samvadadhvam (1957) 1(3), pp. 30-32. 


\section{Socialist statistics in China: adoption and disaffection}

The People's Republic of China had largely stayed outside this newly globalizing world of statistical exchange. Instead, as in several other spheres in the immediate years after 1949, the PRC looked to the Soviet Union as it sought to build its statistical capacity. ${ }^{27}$ The result was the rejection of statistics as a universal science, a notion that was labelled a Western, bourgeois conceit. Instead, statistics was reformulated as a social science in service to building a socialist society, bifurcating it - rhetorically and substantively from what was considered the tainted, bourgeois and socially unproductive pursuit of mathematical statistics. The Chinese economist Di Chaobai 狄超白 (1910-1978) had clarified this position as early as 1951 in his message at the International Statistical Institute's biannual conference in New Delhi, noting, 'we are of the opinion that the theories, methods and systems in connection with statistics adopted in a country cannot but be closely linked with the social system of the country in question' ${ }^{28}$ Such an understanding, combined with suspicions about the ideologically compromised nature of the ISI, had led the Chinese to reject Mahalanobis's invitation to participate in the setting up of an Asian Statistical Association in 1951. This exercise in 'boundarymaking' was reaffirmed following a 1954 conference in Moscow, and would remain influential in the PRC well into the 1970s. ${ }^{29}$

The practical implications in the People's Republic of this circumscribed definition of statistics were twofold. Within the academy, the study of statistics stood divided. The discipline of statistics, now defined as a social science, was taught in statistics departments where the focus was primarily on procedure, methodology and work. Mathematical statistics, that 'unproductive' and bourgeois pursuit with its reliance on probabilistic methods, was banished to mathematics department. As a result, much like in the Soviet Union, the theoretical and practical arms of statistics were separated, denying the possibility of mutual cross-pollination or the discovery of new theories and methods through application, experimentation and testing. Outside the academy, in the world of statistical work, the impact was just as significant, and resulted in essentially two methods for gathering statistical information: a periodical report system based on complete enumeration wherein paper reports were compiled and supplied to each successive higher administrative level until they reached SSB headquarters in Beijing, and, where complete enumeration was deemed impractical, a system of sample surveys employing typical sampling methods. ${ }^{30}$

27 The larger question of how the PRC built statistical capacity during the 1950s is the subject of my dissertation and book manuscript now in progress. Arunabh Ghosh, 'Making it count: statistics and state-society relations in the early People's Republic of China, 1949-1959', PhD dissertation, Columbia University, 2014.

28 FMA 105-00229-01, 22 (original in English). Di Chaobai (1910-1978) was an economist who was appointed director of the Department of Statistics of the Central Financial and Economic Committee in July 1948. In 1953 he was the head of the Department of Comprehensive Statistics at the SSB.

29 On 'boundary-making' see Thomas F. Gieryn, Cultural Boundaries of Science: Credibility on the Line, Chicago: The University of Chicago Press, 1999. On the 1954 conference see K.V. Ostrovitianov and J.M., 'The discussion on statistics summed up', Soviet Studies (January 1955) 6(3), pp. 321-331.

30 The Chinese is dianxing diaocha or zhongdian diaocha. 'Complete-enumeration periodical-report system' is how the Chinese themselves translated (quanmian) tongii baobiao zhidu. FMA 105-00530-05, 11-12. 
Within a few years, the constraints imposed by the methods of socialist statistics became impossible to ignore. For a country with limited technical resources and a limited supply of trained personnel, yet saddled with an enormous agricultural sector and the largest population in the world, the challenges posed by complete enumeration were legion. And they were made harder still by the employment of the periodical-report system. Paper reports, full of tables and summaries, were generated at each level of administration. Very soon, not only Beijing, but also every administrative level, was complaining of a flood of papers and numbers, and little capacity to make any sense of them. Excess issuing (lanfa) of reports was a problem that drew the attention of all levels of the statistical system. Even though repeated attempts had been made to tackle the problem, it remained a constant feature of statistical work into the second half of the decade. ${ }^{31}$

The reliance on purpose sampling also generated problems. Where complete enumeration was not deemed possible, such as in accounting for total area under crops or calculating agricultural yield, the method of purposive sampling was employed. As Mahalanobis would himself later explain,

An attempt is made to select sample-units (agricultural fields, households etc) which are typical or have characteristics close to the average ... It is now recognized that the method of 'purposive sampling' is not scientifically correct. The only sound method is 'random or probability sampling' which can be relied upon to supply truly representative results; and which alone makes it possible to calculate valid estimates of the sampling error. ${ }^{32}$

Chinese statisticians were thus frequently stuck with estimates that did not accurately represent any reality on the ground. Claiming that a particular village or tract of land was representative of an entire county, and using numbers gained from a close analysis of its characteristics, only led to inaccurate estimates. These estimates, upon collation with other inaccurate estimates, helped compound errors, and could eventually result in data that bore little relation to any reality on the ground.

By 1956, the adoption of socialist statistics presented three sets of challenges to Chinese statisticians. First, by not taking into account the greater challenges posed by China's larger population and predominantly agrarian economy, it demonstrated a rigidity that rendered it incapable of adapting to local conditions. Second, the insistence on using exhaustive enumeration and purposive sampling as the basis for statistical work meant that they had a smaller toolkit devoid of emergent and potentially powerful technologies such as random sampling. Finally, and most damningly, the methods had not been able to deliver the desired results, something best articulated by Wang Sihua, who noted that statistical work remained unable to address the needs of the Planning Commission and the demands of the nation's leaders. ${ }^{33}$

31 See, for instance, Beijing Municipal Archives, Beijing (subsequently BMA), 133-001-00091; BMA 008011-00054; BMA 002-020-00670, 28, 30-32; BMA 002-005-00088; and BMA 133-001-00043.

32 P.C. Mahalanobis, 'Some impressions of a visit to China 19 June-11 July 1957', unpublished manuscript, PCMMMA, 1957, pp. 4-5.

33 Wang Sihua, 'Jieshao yindu tongji gongzuo, jiji kaizhan quanguo chouyang diaocha', Tongji gongzuo (1957) 6, pp. 8-10, 17. The article was reproduced in Wang Sibua tongji lunwenji, Beijing: China Statistics Press, 1986, pp. 95-102. 


\section{Silver jubilee assessments}

It is precisely at this moment that the statistical contacts with India were re-established. That the Chinese were willing to explore solutions in, and in cooperation with, India was perhaps no longer as inconceivable as it had been in 1951. Frustration with Soviet expertise and methods had already led Zhou Enlai to demand that the People's Republic not neglect advances made in capitalist countries. ${ }^{34}$ India was a useful middle ground, where the intellectual and policy environment was open to a variety of perspectives. And in the wake of the Panchsheel Treaty (Five Principles of Peaceful Coexistence) of 1954 and the Meeting of Afro-Asian Countries in Bandung in 1955, Sino-Indian relations had also improved tremendously.

While the re-engagement in statistics occurred within this improved bilateral milieu, it was the visit to Beijing of an Indian Planning Commission delegation in the summer of 1956 that set the ball rolling. The delegation was to have been led by Mahalanobis himself but an illness forced Pitambar Pant to take over. The delegation spent a total of forty days in the People's Republic. ${ }^{35}$ During that time they held over thirty-six meetings with officials, planners and statisticians across several bureaus and also delivered a handful of lectures. ${ }^{36}$ Apart from Beijing, they also toured the famous Anshan steel works and visited the cities of Tianjin, Changchun, Shenyang, Shanghai and Guangzhou. As the ISI annual report noted, such travel 'gave an opportunity to the team to see the work of planning and statistical organizations at the provincial and municipal level'. 37

If they had not been so before, the benefits of mutual exchange and learning seem to have become evident by the end of the trip. Just before departing the People's Republic, the delegation travelled up to the Communist Party summer retreat town of Beidaihe and spent two hours in conversation with Zhou Enlai. Zhou told them that he was particularly impressed with Indian statistical methods in the field of agriculture. He lamented that the Chinese themselves had been using purposive sampling, which had led to non-scientific results. In this matter, India was more advanced (xianjin) than China, and China ought to study India. ${ }^{38} \mathrm{He}$ went on to add that the history of planning in both countries was very short. Their experience was extremely limited, and they had committed errors along the way. But he 'hoped that henceforth [the two nations] could mutually learn from each other'. ${ }^{39}$ Pant's suggestion that an Indian team visit the following year was warmly received. So was his suggestion that one to three Chinese planners be sent to the Indian Planning Commission for a period of six to twelve months. ${ }^{40}$ Finally, Pant also delivered an invitation to the silver jubilee

34 Zhou Enlai, 'On the question of intellectuals', in Robert R. Bowie and John K. Fairbank (eds.), Communist China 1955-1959: Policy Documents and Analysis, Cambridge, MA: Harvard University Press, 1963, pp. 128-144.

35 They entered the PRC through Shenzhen on 8 July 1956 and departed on 17 August.

36 Indian Statistical Institute, Annual Report, April 1956-March 1957, Kolkata, 1957, p. 84.

37 Indian Statistical Institute, op. cit. (36), p. 84.

38 FMA 105-00487-02, 5.

39 FMA 105-00487-02, 9.

40 FMA 105-00487-02, 30. 
celebrations of the ISI in Calcutta in December of that year. Zhou not only confirmed Chinese participation but added that a study team would also be sent to the ISI. Then, for good measure, he added, 'I myself hope that I [too] will be able to meet with Professor Mahalanobis when I am in Calcutta in mid-December.'41

Not only did Zhou himself find time to personally visit the ISI on 9 December 1956, but he was followed within two days by a four-member delegation led by Wang Sihua. ${ }^{42}$ The delegation's first task was to attend the ISI's twenty-fifth anniversary celebrations. Wang later reported that the People's Republic and the Soviet Union were the only two countries to have sent official delegations. Representatives of twelve other countries - all 'capitalist' ones - were present in a personal capacity, and included such notable figures as Ronald A. Fisher of the United Kingdom and the Americans Jerzy Neyman and Morris H. Hansen. ${ }^{43}$ In his congratulatory message, Wang lauded the achievements of the institute, reserving special praise for the advances made in sample surveys and agricultural statistics:

In these fields, the Indian Statistical Institute has accumulated not only data for planning and policy making, but also a great amount of valuable experience and methods, which will not only be useful to India but also to other countries including China.

Wang highlighted the similarities that existed between the two countries and said that Chinese statisticians hoped to follow Chairman Mao's instructions that one must learn from other countries by learning from Indian statisticians. ${ }^{44}$ With the niceties taken care off, the delegation then proceeded to spend over a month studying statistics and statistical methods.

Within a month of the delegation's return to Beijing, Wang published a report in the SSB journal Statistical Work, summarizing the delegation's findings and putting forward its recommendations. ${ }^{45}$ Wang described India as an agricultural nation with over fifty million households, immediately drawing strong links to the reality as it obtained in the People's Republic as well. To carry out complete enumeration would not only require a huge number of investigators but also be uneconomical. And the entire process from designing a complete enumeration to collection, analysis and publication would take anywhere from one to two years. Compared to this, sample surveys were much quicker and only needed a small number of investigators who would be sent to a small number of sample households. Wang explained that the Indians believed

41 FMA 105-00487-02, 3.

42 Samvadadhvam (1957) 1(3), p. 20.

43 Wang Sihua, 'Kaocha yindu tongji gongzuo de baogao', report delivered at the 6th Annual Statistical Work Conference in Beijing, September 1957, published in Tongji gongzuo zhongyao wenjian huibiandisanji, Beijing: Statistical Press, 1959, pp. 90-97, 90. The other countries included the Netherlands, the United States, Lebanon, Thailand, Pakistan, Japan, Switzerland and the United Kingdom. See Samvadadhvam (1957) 1(3).

44 Samvadadhvam (1957) 1(3), p. 16.

45 Wang, op. cit. (33). Dai Shiguang, Wang's fellow delegation member, also wrote an article on India's sample survey system but it was entirely factual in nature and did not seek to make any recommendations. See Dai Shiguang, 'Yindu de quanguo chouyang diaocha: shehui jingji diaocha', Tongji gongzuo (1957) 9, pp. 2-6. 
sample surveys were cheaper, quicker and more accurate and that random sampling was the best way of avoiding bias. As a result, the principal method of collecting data remained sample surveys. Besides a decennial census, five-yearly farm and livestock census, and annual census of twenty-nine heavy industries, all other kinds of data, relating to income, production, economic conditions in rural and urban areas, urban employment, etc., were collected using sample surveys. The delegation was impressed with the numbers involved in statistical work and the relative abundance of published material on sampling. Statistical training, too, seemed to be more widespread than in China. Fifteen of the thirty-three national universities possessed departments of statistics or offered training programmes and altogether two thousand students were engaged in the study of statistics.

Wang identified three important characteristics of sample surveys in India. The first was that they were in widespread use, and often national in scope. This was significant because India stood far ahead of other capitalist countries in its employment of sampling technology. National sample surveys had been carried out in industry, agriculture, animal husbandry, household industry, transport, commerce and services, as well as on urban workers' livelihoods and rural cost of living and income. A second characteristic was that the use of interpenetrating samples allowed sample surveys to be carried out continuously. Accordingly, it was possible to check and cross-check results and easily discover errors. In addition, all methods of examination and verification, including purposive ones, were used to raise the quality of the data. Finally, sampling work was closely tied to policy making in India, and so it received the attention and support of the government.

Having worked hard to establish the usefulness of sampling, Wang turned his attention to making his recommendation: to 'energetically launch national-scale sample surveys in our country, and extensively collect [data] on every aspect of social and economic activity'. ${ }^{46}$ Wang bemoaned the recent status of statistical work in the PRC. On the one hand, statistical forms were too many, to the point of excess (taiduo tailan), while, on the other, the statistical materials so produced were unable to completely satisfy the needs of the Party leadership. According to him, such an irrational situation needed to be swiftly remedied. And the only way to stop or limit the excess issuing of unscientific or fiscally wasteful reports by various departments was to speedily adopt the use of scientific sample surveys. But China's planning apparatus was still rather rudimentary, and its society complex. Wang conceded that the complete-enumeration periodical-report system remained useful for tracking production and circulation. But when it came to economic activities on a national scale, especially those dealing with the complex issues of allocation and expenditures, pursuit of complete enumeration at the ground level only resulted in all the data and indicators being flooded in needless trivial details. In conclusion, Wang declared that only by organizing specialized scientific sample surveys could the Chinese get twice the result with half the effort. ${ }^{47}$

46 Wang, op. cit. (33), pp. 100-101.

47 Wang, op. cit. (33), pp. 101-103. 


\section{'And next year in Peking'}

At about the time when statisticians, planners and leaders were reading Wang Sihua's exhortation to adopt sample surveys, deliberations were initiated by the SSB to invite Mahalanobis to the People's Republic for a lecture and discussion tour. ${ }^{48}$ In March, the Foreign Ministry informed its embassy in Delhi that the SSB, Renmin University and the Economic Research Institute of the Chinese Academy of Sciences would jointly invite Mahalanobis to the People's Republic. ${ }^{49}$ The host institutions identified two principal areas of interest: problems relating to statistical sample surveys and the achievements and applications of mathematical statistics. Of particular interest to the Chinese was how to select an adequate number of representative samples and test the quality of data they produced. In a letter dispatched to the Foreign Ministry, Wang Sihua himself articulated additional topics to be forwarded to Mahalanobis: India's experience with planning nationwide sample surveys, and statistical quality control of industrial products in India. ${ }^{50}$

In return, the SSB acknowledged that Mahalanobis hoped to resolve three requests of his own while in the People's Republic. The first was to organize visiting students who would travel to India for study, the second was to have specialists sent to the Indian Statistical Institute to help with translating materials from Chinese, and the third was an interest in understanding the training of health services personnel in China. The SSB acknowledged not just that Mahalanobis was India's premier statistician and the moving intellectual force behind its second Five Year Plan, but also that he enjoyed much international fame. In receiving him an attitude of sincere and genuine friendship was to be adopted, thereby advancing Sino-Indian friendship generally, and closer ties in statistical science in particular. Ideological differences ought to be set aside. The guiding principle would be to 'seek common ground while accepting differences' (qiutong cunyi).

Mahalanobis entered the People's Republic via Shenzhen on the morning of 19 June 1957. Accompanying him were his wife, and the noted statistician and specialist in sampling methodology D.B. Lahiri. The following morning they visited the Sanyuanli Agricultural Production Cooperative within the city and 'saw the system of maintaining the village statistical records, and got acquainted with the method of "purposive sampling" which was being extensively used for estimating agricultural production and for family budget enquiries'. ${ }^{51}$ Later that day, they also attended a short presentation on the nature of sampling work done in the province. Mahalanobis was immediately suspicious when told that the error in the sample surveys was barely 2 per cent. He remarked that for such purposive sample surveys the error ought to be much higher, adding that in the Soviet Union it was in the order of 15 per cent, in the United States

48 Unless specified otherwise, the primary source material for Mahalanobis's activities in China is FMA 105-00530-06. This archival file consists of a series of fourteen bulletins issued by the office in charge of handling his affairs (jiedai bangongshi) and covers the entire duration of his stay in the People's Republic.

49 FMA 105-00530-05, 3.

50 FMA 105-00530-05, 13-18.

51 Mahalanobis, op. cit. (32), p. 1. 
12 per cent, and in countries such as Germany and Japan it was above 10 per cent. The only way to carry out reliable surveys was to use random sampling, he exclaimed.

Over dinner later that evening Mahalanobis urged his hosts not to be too dogmatic in their approach to statistics. He told them that 'even though the Soviet Union was the first nation to establish socialism, many of its statistical methods are too old and not easy to change anymore'. ${ }^{2}$ Through his visits to the Soviet Union and his numerous interactions with its leading statisticians and economists Mahalanobis was well aware of the status of statistical research and work there. Three years earlier, he had written to Pitambar Pant noting that 'one orthodox viewpoint in USSR has been to exclude mathematics from economics; to insist on statistics to be almost exclusively the handmaiden of economics; and to separate mathematical statistics as a separate (and somewhat abstract) subject under probability and mathematics'. ${ }^{53}$ In his unpublished report on the China tour he would add that in spite of much discussion, 'statistical practice in USSR, however, still continues to be based on "purposive sampling", 54 The situation he encountered in China was similar, but his very presence there suggests that the Chinese were aware of the limitations imposed by their methodology. And discussions over the following three weeks would indeed indicate to him that the Chinese were 'keeping an open mind' to the possibilities offered by mathematical statistics. ${ }^{55}$

The delegation's work began in earnest on 24 June with a briefing by Xue Muqiao 薛 暮桥 (1904-2005), the director of the SSB. Xue explained that over the course of the preceding five years an integrated statistical system modelled on that of the Soviet Union had been set up and reached down to the level of village cooperatives all over the People's Republic. With a staff of about 650 personnel, the SSB headquarters served as the apex body of this system and was responsible for collection and auditing of all statistical data and its subsequent delivery, as required, to various government agencies. Below it, at the provincial level, statistical offices coordinated work across the roughly 2,200 counties in the country. Under the counties were the village administrations, which coordinated the statistical work of about 750,000 village cooperatives. In line with the Soviet model, the scope of statistics was 'comprehensive' and covered population, agriculture, industry, transport, trade, consumption, health, education, finance, national income, employment and so on. ${ }^{56}$

Xue then proceeded to explain the methodology employed by the SSB. The preferred choice was complete enumeration. This worked rather well in several sectors. In the industrial sector, three thousand units sent monthly returns and sixty thousand submitted annual reports. In construction, about a thousand of the most important projects reported monthly, with the rest doing so on an annual basis. Reports from the railways,

52 FMA 105-00530-06, 3.

53 Mahalanobis to Pitambar Pant, 3 July 1954, Papers of Pitambar Pant (190 LII), Nehru Memorial Museum and Library, New Delhi, p. 49.

54 Mahalanobis, op. cit. (32), p. 5. Later in the trip he would inform his hosts that ever since 1947 the Soviet Union had not attended any sample-survey activities organized by the International Statistical Institute. FMA 105-00530-06, 15.

55 Mahalanobis, op. cit. (32), p. 6.

56 Mahalanobis, op. cit. (32), pp. 1-3. 
shipping and trucking were submitted monthly, as were government purchase and the consumption of important commodities. The agricultural sector, however, posed a much larger problem. The provincial bureaus had their hands full trying to completely enumerate the 750,000 village cooperatives. Delays were the norm, and the accuracy of the results was not high. As a result, in 1955, an initial attempt was made to calculate the yield of crops per unit area over a large part of the country using sample survey techniques. In addition, sample surveys had been carried out in order to better assess the standard of living of rural, working-class and urban households. For instance, a rural survey in 1955 had covered 15,000 farm families across twenty-three provinces and an urban survey in 1956 had included six thousand families. Xue clarified that the technology used was purposive sampling, and concluded by observing that through increased contact with India, and in particular following the Wang Sihua delegation's visit to India, the Chinese had become particularly interested in learning from India's expertise and experience in carrying out random-sample surveys. ${ }^{57}$ Mahalanobis would later claim that after this 'brilliant survey', both he and Lahiri had a much clearer sense of why the Chinese 'were so deeply interested in sample surveys and mathematical statistics'. 58

With their brief firmly established, Mahalanobis and Lahiri set about preparing their lectures. Over the course of the following two weeks they led eight group discussions on sample surveys and delivered a total of nine lectures. The group discussions usually lasted from three to four hours and were frequently quite technical in nature. Of the nine lectures, Mahalanobis delivered five and Lahiri four. The lectures were usually day-long affairs, divided into two three-and-a-half-hour sessions. Mahalanobis delivered two lectures on 'Sample surveys' at the SSB, one on 'Planning in India' at the Planning Commission, and two on 'Recent developments in the theory and applications of mathematical statistics' at Beijing and Renmin Universities. For most of these lectures the audience, comprising as many as three hundred people, included statisticians, economists and senior mathematics students. ${ }^{59}$ Lahiri's four lectures were similar in format, though he spoke exclusively on 'Applications of the theory of mathematical probability in sample surveys'. Two of these were delivered at the SSB, one at Renmin University, and one at the Chinese Academy of Sciences. Lahiri's lectures were especially technical and the audience was restricted to thirty to thirty-five persons familiar with statistical work and knowledgeable in mathematics. ${ }^{60}$

The principal content of all the lectures and group discussions (the lecture synopses, lecture transcripts, subsequent questions and answers, as well as the minutes from the

57 Much of the description in the above two paragraphs is from Mahalanobis, op. cit. (32), pp. 3-4.

58 Mahalanobis, op. cit. (32), p. 1.

$59 \mathrm{Ni}$ Jiaxun 倪加勋, then an undergraduate at Renmin University, recalled attending one of these lectures. According to him, most in the audience did not follow much of what was said. He remembered it as an important event at the university, however. I conducted two interviews with $\mathrm{Ni}$ in Beijing in 2011, on 29 March and 7 September.

60 Mahalanobis, op. cit. (32), pp. 6-7. On Lahiri's lectures, the SSB Bulletin from 5 July stated that there were over twenty people present and that the 'discussion was a little too specialized, a little too technical in nature'. FMA 105-00530-06, 62-63. 
group discussions) was compiled, translated, edited and published a year later by the Statistical Press. ${ }^{61}$ The foreword of this publication granted that there were specific points on which the Indians and the Chinese did not see eye to eye, but advocated that in spite of those differences, the Chinese needed to pay greater attention to the science and technique of sample surveys. The book was produced, therefore, as a reference for future research and discussion on mathematical statistics and sampling. Its distribution, however, was most likely limited to statistical bureaus and offices across the country. Whether it entered curricula at teaching institutions or was used in any other specific way remains unclear.

\section{Meeting vice-premiers and the premier}

Mahalanobis had the opportunity to discuss statistics with the PRC's political leadership on two separate occasions. On 3 July Mahalanobis and Lahiri met with vice-premiers Li Fuchun 李富春 and Bo Yibo 薄一波 (1908-2007). ${ }^{62} \mathrm{Li}$ and Bo were also chairmen respectively of the Planning and Economic Commissions and Li was also the minister for statistics. At the meeting, Mahalanobis reiterated the advantages of random sampling - that it was faster, cheaper and more accurate, and its error easier to ascertain. With a national-scale sample survey in place, he claimed, one would need only four to eight weeks to get a sense of socio-economic conditions across the country. On specific techniques, he recommended the use of interpenetrating samples and probability sampling. Given China's 2,200 counties, Mahalanobis estimated that the sampling bureau could begin with a staff of about two thousand. Work could initially begin in five or six provinces, and as it intensified each county would be assigned two surveyors on average, resulting in total staff numbering between four and five thousand. Transcribers, human computers and statisticians would, of course, also be required. Mahalanobis urged that a training institute along the lines of the ISI be set up, so that not just statistical workers, but also a highly specialized cadre of statisticians, could be trained. This institute would also foster closer ties with the Chinese Academy of Sciences, and more generally between statistics and the disciplines of mathematics and economics - 'this was the way of the future'. Receptive to these ideas, $\mathrm{Li}$ and Bo requested that Mahalanobis bring them up during his forthcoming conversation with the premier later in the week. Both were particularly keen to see sample survey work begin as soon as possible. And yet lingering doubts about sampling technology remained. Li specifically enquired whether 'on the matter of the accuracy of sample surveys, Professor Ma could once more carry out discussions with the SSB'.63

Mahalanobis also took the opportunity to reiterate his specific proposals for enhanced Sino-Indian cooperation in statistics and planning. He requested that the Planning Commission and the SSB arrange for the regular forwarding of technical data to the Indians. He suggested that a small 'China Unit' be set up at the ISI. This unit would

61 Yindu mahalanuobisi jiaoshou fanghua tongji baogaoji, Beijing: Statistical Press, 1958.

62 FMA 105-00530-06, 53-60.

63 FMA 105-00530-06, 53-60, 57. 
help translate into English important Chinese publications, articles and technical data; teach Chinese to a few statisticians and professors; and maintain direct links with Beijing. To staff this unit he requested that one or two people be sent over, and assured the Chinese that all their costs would be borne by the Indian side. In return, he happily offered to share materials for the teaching of statistics, and also impart training to those Chinese who visited the ISI. He hoped that three to four people would be sent to India for further study and that this would later become an annual practice. Indian specialists in sample surveys, mathematical statistics and other areas could also be sent to China to help in further research, training or the drafting of technical schemes. Li and Bo agreed with this advice and indicated that the details could be worked out with Xue Muqiao and Wang Sihua, both of whom were also present at the meeting. ${ }^{64}$

About a week later, on 9 July, Mahalanobis, his wife and Lahiri were invited to dinner with Zhou Enlai and his wife. ${ }^{65}$ Xue Muqiao and Wang Sihua were also present, as were the Indian ambassador, R.K. Nehru and his wife. Mahalanobis repeated much of what he had told Li and Bo. He was pleasantly surprised to discover that Zhou had been kept informed of his activities and had 'studied some of the rather technical points in my recommendations as he asked some searching and critical questions on the methods of assessing the accuracy of the results of sample surveys' ${ }^{66}$ The premier agreed in principle with most of Mahalanobis's suggestions. He welcomed Indian help in the organization of statistical work and research, and expressed interest in continuing the exchange of personnel, expertise and experience. He also told Mahalanobis that while it may be difficult to send experts immediately to lecture on Chinese statistics and planning, the two SSB staffers who would be sent later in the year could help get the work of the Chinese Unit started. The dinner was a pleasant affair and was subsequently reported upon in the People's Daily with an accompanying photograph of the group. ${ }^{67}$ On 12 July Mahalanobis and company left the People's Republic the same way they had entered, via Shenzhen, assured that exchanges and future cooperation had been put on a solid footing.

\section{Domestic difficulties}

A couple of months after Mahalanobis's return to India, Wang Sihua addressed the 1957 Conference on National Statistical Work. His speech, entitled 'Report of an inspection of statistical work in India', started by referring his audience to his article from earlier in the year. ${ }^{68}$ Wang stated that he had already covered the general outlines of statistical work in India in that piece and would not revisit trodden terrain. Instead, he wanted to focus exclusively on sample surveys. His report was less enthusiastic, more guarded and more strategic than his February article.

64 FMA 105-00530-06, 47-48.

65 FMA 105-00530-06, 68-71.

66 Mahalanobis, op. cit. (32), p. 10.

67 People's Daily, 10 July 1957, p. 1.

68 Wang, op. cit. (43), pp. 90-97. 
Wang now took pains to stress not only that Mahalanobis was aware of Soviet statistics, but also that he knew that Chinese statistics was largely a product of learning from Soviet experience. As a socialist country, Wang acknowledged, the People's Republic should, of course, use a system of complete enumeration as the main methodology, but it was also important to study other methods, something which had not been done sufficiently before:

There are those who are suspicious: Does our visit to India mean that we have changed our policy of learning from the Soviet Union? Such an understanding is in error. Our India visit and Professor Ma's [Mahalanobis's] coming to the People's Republic absolutely do not mean that we have abandoned [a policy of] learning from the Soviet Union ... But, at the same time, we must also study those methods of capitalist countries that are relatively good, especially the methods of sample surveys and the problems relating to statistical technology. ${ }^{69}$

Wang then went on to outline the nature of sampling work in the Soviet Union, providing evidence of its use for decades. He reminded everyone that Soviet specialists were the ones to design the rural-livelihood survey. It was only after this that he began a detailed discussion of India's sampling work, concluding with a list of four advantages: the scale and nature of sample surveying in India were larger and more expansive than in England, the United States and other capitalist countries; the Indians had made new contributions to the technology of sample surveys, namely the methods of continuous sampling (lianxu chouyang) and interpenetrating samples (jiaodao chouyuang); they had carried out detailed comparative research and experimentation on various survey methods; and finally the contents of the surveys were tailored to meet practical requirements. ${ }^{70}$

What was known to Wang and many of his comrades in Beijing had to be communicated more effectively, and subtly, to the various regional representatives at the conference, and through them to the vast numbers of statistical workers across the country: sampling was a general category that included purposive sampling as well as random sampling. And what were new and particularly relevant to the People's Republic were the Indian random-sampling methods, not the prevailing Soviet methods. Wang adopted a two-stage strategy to bring this point home. He first differentiated sample surveys from complete enumeration, highlighting advantages already familiar to us: sample surveys were cheaper and required fewer personnel, and since their scale was smaller than complete enumeration, they could accommodate many more indices and much greater complexity. ${ }^{71}$ Having established the usefulness of sample surveys, Wang proceeded to differentiate what he called subjective (zhuguan) sampling from random or stochastic (suiji) sampling. But he did not advocate the abandonment of older forms of sampling. As long as a method was scientific it ought to be used. What, then, was the definition of 'scientific'? For Wang, a method 'was scientific only if it could truly reflect the objective situation'. ${ }^{72}$ Thus subjective sampling, under the right conditions of the Party's Mass Work Line (qunzhong gongzuo luxian), could be

69 Wang, op. cit. (43), p. 91.

70 Wang, op. cit. (43), p. 94.

71 Wang, op. cit. (43), p. 95.

72 Wang, op. cit. (43), p. 96. 
scientific too. Wang pointed out that the method of purposive (or typical) surveys had not been effective in the past because the selection of typical cases had not reflected objective reality. The task, as it lay before them, was to carry out small-scale experiments to find out which method would be most suitable. ${ }^{73}$

The transformation from February to September was stark. From the vigorous promotion of establishing nationwide sample surveys, the mood had shifted to one of qualified, even muted, endorsement. After several years of denigrating 'capitalist' statistics, Wang had uncharacteristically written favourably about them in February. This speech, seven months later, suggests he had not struck enough of a conciliatory tone in the earlier article and, therefore, had to make amends. Indeed, Wang's speech at the conference can be read as an exercise in persuasion meant to assuage reactionary cadre who feared not just ideological compromise, but also, perhaps just as importantly, being shifted out of their comfort zones and established statistical practices. Larger domestic political currents also no doubt played their part. Starting with the Hundred Flowers movement in 1956, when free expression was encouraged, the political climate had been relatively conducive to the exploration of new possibilities. In June 1957 the Anti-Rightist campaign began, leading to the narrowing of those possibilities, and no doubt to the much more cautious tone adopted by Wang in September. A couple of months later the xiafang movement began with cadres being sent down to factories and villages to work with their hands. The movement was later extended to intellectuals as well. Under the circumstances, advocating capitalist methods could no longer just be a matter of their scientific-ness.

\section{The study tour of 1958}

It was in this somewhat confused milieu, where intellectuals and city-dwellers faced the prospect of manual labour in the countryside, that Wu Hui 吴辉 and Gong Jianyao 龚 鉴尧 found themselves on a mission to India. ${ }^{74}$ Born within a year of each other in the late 1920s, Wu and Gong had received degrees in statistics from Chongqing and Nanjing Universities respectively in 1950. They were part of a whole generation that had been introduced to and trained under an inclusive understanding of statistics, which drew from texts and materials from the United States and Britain, as well as the Soviet Union. After 1949, they had to recalibrate their training to serve the newer and narrower definition of statistics as a social science within the People's Republic. By the mid-1950s both were working at the SSB headquarters in Beijing. In 1957, they were among ten young cadres shortlisted for additional testing to determine who would be sent to India. In the end, Wu and Gong's facility with the English language, coupled with their specializations in the key areas of focus - industrial and agricultural statistics proved decisive.

73 Wang, op. cit. (43), p. 96.

74 Unless otherwise noted, this section draws primarily on oral-history interviews conducted with Gong Jianyao and Wu Hui. I met Wu in Beijing on 8 September 2011. I met Gong, who lives in Guangzhou, a week later on 14 September 2011. 
The duo arrived in Calcutta on 4 January 1958. Their official status was that of visiting scholar (fangwen xuezhe) and, unlike the dozens of students from various Asian countries being trained at the ISI's International Statistical Education Centre, they were not required to attend classes. Instead, they were given study spaces and permitted to conduct their own independent reading and research. The primary focus of their work was the study of Indian sampling techniques. This they began by reading all previous documents and publications relating to the ISI's statistical sampling activities, which were held in the ISI library. From there, they moved to a close study of the theory and methods of sampling. In the process, they studied simple random sampling, stratified random sampling, cluster sampling, double sampling, multi-stage sampling and other sampling methods. Periodically, they would meet with Mahalanobis, Lahiri or C.R. Rao and discuss progress made and problems encountered. ${ }^{75}$ D.B. Lahiri in particular was their principal guide and interlocutor. Exposure to the latest Western texts on statistics and sampling rounded off their readings.

While the bulk of their work was theoretical or centred on book-learning and based at the ISI, Wu and Gong also had the opportunity to gain first-hand experience by participating in two sample surveys. The first of these was a land-use sample survey where they witnessed the Mahalanobis-devised method of cutting circular crop samples in fields. The second was a family budget survey carried out in Calcutta. Other activities included sitting in on meetings of the National Sample Survey (NSS), where sampling teams would report their recent experiences and problems, and discuss solutions for the next round of the NSS. Both Wu and Gong also had the opportunity to interact with the various Indian and foreign statisticians present at the ISI during 1958. During the year they also visited Bombay, Pune and Delhi, as well as several paddy and jute sample survey sites across the country. ${ }^{76}$

While Gong and Wu were in India, events within the People's Republic had pushed statistics, as they had just about everything else, in new directions. Gong recalled reading about the Great Leap Forward in the papers and receiving letters from friends and family describing the push towards collectivization. Wu also remembered discussing the agricultural growth results of the Great Leap Forward, claiming that Gong was openly suspicious of them. Statistics, too, they were informed in time, was changing. In August 1958 an 'on-the-spot meeting' (xianchang huiyui) was held in the town of Baoding 保定, just south of Beijing. ${ }^{77}$ At this meeting, statistical work carried out over the previous seven years was repudiated and a call was made for a Great Leap

75 Both Wu and Gong recalled Mahalanobis fondly, observing that he left a rather deep impression on them. In a 2001 article published in China Statistics, Gong went so far as to claim that two professor Mas had played a hugely inspirational and instrumental role in his life. The first was Ma Yinchu 马寅初 (1882-1982), the wellknown economist and one-time president of Beijing University, persecuted during the late 1950s for his championing of birth control. The second Professor Ma was none other than Mahalanobis himself. See Gong Jianyao, 'Shidao qinghuai', China Statistics, May 2001, pp. 52-54.

76 Gong Jianyao, 'Woguo chouyangfa yanjiu yu shijian de fazhan', Xi'an tongii xueyuan xuebao (1994) 2 (9), pp. 7-14, 10 .

77 See, for instance 'Zhaokai quanguo tongji baoding xianchang huiyi de baogao', in Tongji gongzuo zhongyao gongzuo huibian, vol. 3, Beijing: Statistical Press, 1959. 
Forward in statistics. As Gong would explain decades later, the logic was straightforward:

[With] the collectivization of peasant production and consumption, all [statistical] data could basically be obtained [directly] from the communes. The peasant family revenue and expenditure survey, which had been set up on the basis of surveys of sample households, had fulfilled its historical obligation/role [lishi shiming]..$^{78}$

In one fell swoop, established statistical systems, including the complete enumeration and purposive sampling already in place, as well as future potential surveys based on random sampling, were all consigned to history. The Sino-Indian exchanges and much-touted statistical cooperation, too, were to become a victim of this development. Towards the end of their India stint, Wu and Gong had worked hard to draft a lengthy report of their activities in India and their recommendations for future statistical work in China. Upon their return in early 1959, it too 'had to be rewritten and was converted into a simple report, submitted to the SSB's leadership to be read and dismissed [canyue liaoshi]'. ${ }^{9}$

\section{Conclusion: things fall apart}

On the international stage, events were to overtake the Sino-Indian statistical exchanges as well. Disagreements over the Sino-Indian border, which had existed since the start of the decade, began to dominate diplomatic exchanges as each side hardened its position. The ensuing frosty relations no doubt served to reduce some of the spirit of Bandung and endanger the Panchsheel principles. It is unclear to what extent Mahalanobis and the ISI were aware of these differences or of the major upheavals within the People's Republic. In October 1958, Mahalanobis lobbied the Chinese to send a couple of planners with expertise in heavy industries to help with the drafting of India's third Five Year Plan. ${ }^{80}$ He lamented that the half-hearted development of heavy industries in India during the years of the second Five Year Plan had been a big mistake and wanted to take advantage of China's direct experience in this area. The Chinese embassy in New Delhi duly forwarded Mahalanobis's request to the Foreign Ministry in Beijing. The Foreign Ministry, in turn, asked the Planning Commission for advice on the matter. In doing so, they added that were Chinese experts to be sent, their primary goal would be to 'expand our country's influence'. ${ }^{81}$ After additional deliberations that stretched into early 1959 , it was eventually agreed to send a three-man team, which was instructed to serve only as consultants and introduce China's recent experience in heavy industries. Under no circumstances were they to offer advice on Indian problems. The Chinese embassy in New Delhi wrote back in early March stating that Mahalanobis welcomed the Chinese experts and hoped they could visit from April to June. ${ }^{82}$

78 Gong, op. cit. (76), pp. 10-11. During my interview with him, Gong recalled how bad an effect the Baoding meeting had on statistical work.

79 Gong, op. cit. (76), p. 11. Both Gong and Wu would play major roles in subsequent years in statistical work and were important players in the post-1978 reform of statistics.

80 FMA 105-00647-02, 1.

81 FMA 105-00647-02, 4.

82 FMA 105-00647-02, 5-9. 
The archival trail turns cold after this. On 10 March an uprising occurred in Lhasa and by the end of the month the Dalai Lama and several tens of thousands of his followers had escaped to India. They were granted asylum and allowed to settle in the northern hill resort of Dharamshala. At a scientific conference held in Moscow in May, a little over a month after the Dalai Lama's flight from Lhasa, Mahalanobis bumped into the Chinese physicist Zhou Peiyuan 周培源 (1902-1993) and the two engaged in a long conversation. ${ }^{83}$ Zhou later filed a report of this meeting with the Foreign Ministry. ${ }^{84}$ Eight of the report's nine pages were devoted to a discussion of Tibet and geopolitics. Only on the last page did Zhou dwell on a few scientific points that had also come up. As for the three-member Chinese team, it never visited India.

83 People's Daily, 13 August 1959, p. 4.

84 FMA 105-00656-02, 1-9. 